\title{
As "REDUNDÂNCIAS" \\ SÃo MESMO REDUNDÂNCIAS? \\ UMA PERSPECTIVA DiscURSIVA
}

\section{"Redundancies" are really redundancies? \\ A discursive perspective}

\author{
Maria Marta Furlanetto*
}

Por que duas palavras para dizer a mesma coisa? É que aquele que a diz, é sempre o outro.

Nietzsche

\section{INTRODUÇÃo}

O fenômeno da deriva no uso escrito formal do português brasileiro é um tema que venho desenvolvendo há algum tempo. Este trabalho é parte de uma pesquisa que objetiva, além da observação e descrição do fenômeno do ponto de vista discursivo, detectar suas implicações normativas e consequências para a pedagogia da língua. Tenho estudado ocorrências linguísticas em trabalhos acadêmicos, revistas, jornais etc., que vão desde aspectos morfológicos até a organização sintática e semântica (estrutura, concordância, coerência...), tendo como referência metodológica os aparatos de gramatização (gramáticas, dicionários, manuais) ${ }^{1}$. o material de que disponho vem sendo coletado tendo como limite inicial o ano de 1990.

$\mathrm{Na}$ abordagem discursiva, a deriva é vista como um conjunto de deslocamentos em vários níveis e categorias das línguas, de cunho sóciohistórico, com relação a um referencial que é tomado como padrão ("centro") e ao referencial (relativo) representado pelo estado atual (instável) no uso de uma língua. Não se considera, nesse contexto, que haja um "desvio"

- UNISUL.

A gramatização é um processo iniciado no Renascimento europeu "[...] que conduz a produzir dicionários e gramáticas de todas as línguas do mundo [...] na base da tradição greco-latina" (AUROUX, 1992, p. 8). Tratada como revolução tecnológica, a gramatização serve como meio de conhecimento e dominação de culturas. 
relativamente a algo "normal": há um movimento, um processo que pode ser estudado e caracterizado pela observação de inovações que ocorrem no tecido linguístico.

Auroux (1994) fornece ao estudo alguns pressupostos filosóficos sobre hiperlíngua, com os quais pretendo, no conjunto da pesquisa, apresentar uma síntese do funcionamento discursivo do português brasileiro remetendo a considerações sobre o "brasileiro" como uma hiperlíngua. Auroux afirma que uma língua empírica só existe, em determinadas frações de espaço-tempo, através de sujeitos com determinadas capacidades linguísticas, ou ainda “[...] dotados de 'gramáticas' (não necessariamente idênticas), envoltos por um mundo e por artefatos técnicos, entre os quais figuram (às vezes) gramáticas e dicionários”. Isso significa que esse espaçotempo "[...] dispõe de uma certa estrutura, conferida pelos objetos e pelos sujeitos que o ocupam. Denominaremos 'hiperlíngua' a este espaço-tempo assim estruturado" (AUROUX, 1994, p. 243) ${ }^{2}$.

Convém lembrar que o que faço com dados que poderiam ser classificados como "gramaticais" está impregnado do espírito que anima a discussão feita por Franchi (2006, p. 53) sobre criatividade e gramática: "A questão mais importante para a teoria gramatical é a seguinte: por que e como as expressões das línguas naturais significam aquilo que significam?"3. No processo de construção e de representação do mundo pela linguagem, "[...] o sujeito não é somente quem se apropria de um sistema dado, mas quem o constrói junto com os outros, abertas todas as possibilidades de reforma e de relocação." (FRANCHI, 2006, p. 56). Ao falar de gramática, Franchi estava voltado para o texto e para o discurso. Pressuponho também, a partir de Bakhtin (1979, p. 22), que tudo na língua é sintomático do que se passa na vida social: "A palavra é o modo mais puro e sensível de relação social" - ela funciona como um termômetro para determinar os valores ideológicos.

Iniciei meu estudo do fenômeno aqui apresentado alimentando algumas suspeitas e propondo um questionamento: Estariam as redundâncias suprindo alguma lacuna de comunicação? Na fala, elementos de uma sequência podem perder-se para a escuta, mas o regime da escrita é outro. Há "esvaziamento" semântico ou não reconhecimento semântico no uso? A língua se esvazia ou os usuários esvaziam itens lexicais e estruturas? A parafrasagem na formulação discursiva (processo metadiscursivo), através das expressões isto é, ou melhor, ou seja, para ficar mais claro... seria uma das faces desse processo? Que fatores do contexto social estão influindo Orlandi (2001).

2 V. também Auroux (1998), e a coletânea História das idéias lingüísticas, organizada por

${ }^{3}$ Criatividade e gramática começou a circular em 1988, em publicação da Coordenadoria de Estudos e Normas Pedagógicas - CENP (São Paulo). Este e Mas o que é mesmo "gramática"?, de 1991, foram retomados por Sírio Possenti e são apresentados em edição de 2006 com dois outros textos que Franchi partilha com Esmeralda Negrão e Ana Lúcia Muller. 
nesse uso, que se diria (diz), à primeira vista, vicioso? Estas são algumas das questões postas para o desenvolvimento de minha pesquisa - mas neste trabalho devo me restringir a algumas respostas e à proposição de questões adicionais.

Pressuponho, adotando uma perspectiva discursiva, que "dizer a mesma coisa" não equivale a dizer do mesmo modo; discursivamente importa o como se diz e para quem se diz, que imprime ao material linguístico matizes variados. Pressuponho ainda a plurivocidade inscrita nos enunciados, em paralelo com o conceito de univocidade, resultando os dois efeitos de forças que atuam, respectivamente, na desestabilização das línguas e na sua estabilização - envolvendo, neste caso, o processo de interpretação pelo interlocutor.

É comum que se diga que certas interpretações "distorceram" um texto. Assim, uma operação discursiva poderia prevenir a possibilidade de deformação. Pensar dessa forma, na construção dos enunciados, aponta para a relação interlocutiva; representa a perspectiva do outro quando se está no fluxo discursivo, negociando sentidos tendo em vista destinatários reais ou virtuais. As "pistas interpretativas" poderiam retificar certa direção de interpretação e também bloquear certas extensões semânticas de um termo polissêmico. Continuidade e ruptura na enunciação são as duas faces da moeda. Em outras palavras, é o jogo entre identidade e alteridade, entre estabilidade e "deformabilidade". Traços se repetem na voz do locutor, como que manifestando a esperança de que, perdido o da primeira palavra, o outro alcance o destinatário. Em perspectiva mais ampla, o fenômeno pode ser visto paralelamente aos "cortes" (abreviações) do que se considera supérfluo no processo discursivo - tal como -mente numa sequência de advérbios e mesmo o radical numa sequência em que ele se repete: inter $e$ intradiscurso.

\section{INSTRUMENTOS GRAMATICAIS}

Gramáticas e dicionários, como artefatos que compõem a estrutura complexa de uma hiperlíngua, são excelentes materiais históricos na corrente de desenvolvimento das línguas. Vou apresentar e comentar apenas uma amostra, no sentido de fazer observar o caráter de fluidez e circularidade que se pode encontrar nessas fontes, que são referência bastante genérica. Em Cunha e Cintra (1997, p. 607) encontra-se apenas um tópico sobre o pleonasmo - definido como "superabundância de palavras para enunciar uma idéia”. Os exemplos privilegiados são de caráter literário, e os mais triviais são uma representação de fala popular. O pleonasmo é considerado vicioso se seu papel não emprestar vigor ao pensamento.

Por outro lado, Cunha e Cintra chamam "epíteto de natureza" o uso adjetival em céu azul, prado verde, noite escura. Por quê? É que não se trataria de "reiteração inútil": o adjetivo estaria marcando o caráter intrínseco 
ou dominante de um objeto. Os exemplos apresentados são poéticos. Os "objetos pleonásticos" sintáticos fecham o tópico na gramática.

Consulto então um dicionário contemporâneo - o Houaiss (2001). A partir dos elementos a que a descrição remete e aos possíveis membros lexicais do mesmo campo, novos verbetes vão aparecendo e remetendo a outros. Por ex., "redundância" sugere excesso, e aponta para "tautologia".

Tautologia é conceito específico da Lógica, mas também ocorre na gramática. Na retórica, do ponto de vista negativo, remete a expressão que envolve um mesmo conceito repetidamente.

Passando a pleonasmo, encontramos em sua acepção linguística, por um lado, "redundância de termos", às vezes considerada legítima (valor positivo), e por outro "excesso de palavras", circunlocução (valor negativo), o que leva à ideia de superfluidade e inutilidade.

Note-se que se pode passar do sentido de "emprego legítimo" ao de "inutilidade". o termo "paráfrase" não foi usado na descrição dos verbetes anteriores, mas, em sua própria descrição, implica os termos apresentados acima - além de ter importância no contexto dos estudos discursivos (elimino algumas acepções que se afastam muito do que está em questão aqui).

No campo da literatura, paráfrase leva a metáfrase, como estratégia de interpretação ou tradução, e ainda a uma explicação, reapresentação de texto para efeito de inteligibilidade. Mas o efeito de sentido pejorativo também ocorre aqui, pelo viés da prolixidade, da verbosidade. No campo da linguística, pode ter o efeito menos carregado de frase sinônima (relação parafrástica).

Caímos, então, na sinonímia, remetendo à possibilidade de substituições lexicais em contextos específicos. Na perspectiva da estilística e da retórica, obtém-se o efeito de aclaramento, de matização de sentido (exergásia, trabalho de acabamento).

Observe-se que na área de ciências da computação o termo 'redundância' é valorado positivamente, representando um cuidado necessário (segurança). Nesse caso, trata-se de um dispositivo que passa a funcionar apenas quando o principal falha, e não simultaneamente (um nobreak, por exemplo, alimenta o computador quando a rede elétrica é interrompida):

O termo redundância descreve a capacidade de um sistema em superar a falha de um de seus componentes através do uso de recursos redundantes, ou seja, um sistema redundante possui um segundo dispositivo que está imediatamente disponível para uso quando da falha do dispositivo primário do sistema (PINHEIRO, $2004)^{4}$.

\footnotetext{
${ }^{4}$ Disponível em:

$<$ http://www.projetoderedes.com.br/artigos/artigo_conceitos_de_redundancia.php $>$.
} 
No caso dos dados recolhidos, dada a simultaneidade das expressões, há indícios de que alguns traços de significação são desconhecidos ou ignorados, em função da procura de garantia de compreensão por parte de outrem. Assim, traços se repetem na voz do locutor, como que manifestando a esperança de que, perdido o da primeira palavra, o outro alcance o destinatário. Isso se faz comumente alternando-se a classe gramatical usada. Por exemplo:

$$
\begin{array}{ll}
0 & \text { costumar }(V) \text { sair constantemente }(A d v), \\
\circ & \text { oco }(A d j) \text { por dentro }(A d v), \\
0 & \text { planejar }(V) \text { previamente }(A d v) .
\end{array}
$$

Seria de esperar maior frequência nos casos em que as duas palavras em questão sofressem descontinuidade na sequência, mas não é o caso: quase sempre elas estão lado a lado.

Interessa aqui o enfoque dado à repetição de traços semânticos em palavras distintas, e a verificação de como itens lexicais contíguos afetam um ao outro; em suma: os efeitos de sentido que podem provocar. Poderia ser a repetição um recurso retórico? Reformulações parafrásticas (com isto $e ́$, ou seja, ou melhor, em resumo...) funcionariam, assim, como meios de reajuste, de controle dos enunciados ${ }^{5}$.

Marcondes Filho (2002, p. 236) diz que a $2 .{ }^{\mathrm{a}}$ lei da termodinâmica ${ }^{6}$ pode ser aplicada à linguagem:

Uma parcela de incerteza na transmissão de uma mensagem irá reduzir o grau de informação dessa mesma mensagem, gerando mais indeterminação, mais entropia. Se eu lhe informo alguma coisa deixando lacunas, dúvidas, meu interlocutor compreenderá menos. Mas o freio seria a redundância: reforçar a explicação, falar mais, dar mais detalhes, para frear a incerteza.

Pois bem, considerado o levantamento feito, pode-se perguntar: há um limite (qual?) entre o sentido de prolixo, verboso, desnecessário, excessivo e os efeitos discursivos aceitáveis ou mesmo indispensáveis nesse jogo de repetição? ${ }^{7}$ Qual o papel do contexto, dos interlocutores na cena enunciativa? É aí que se torna relevante comparar os termos-chave que surgiram a partir

\footnotetext{
${ }^{5}$ Tem-se aqui uma das possibilidades que dizem respeito à tese de Authier (1995) sobre as não coincidências do dizer - daí o controle mais ou menos cerrado sobre o dizer.

${ }^{6}$ Essa lei diz, em síntese: "Em qualquer máquina em que diferentes formas de energia são transformadas umas nas outras existe sempre uma quantidade de calor perdida, não recuperável" (ATLAN apud MARCONDES FILHO, 2002, p. 238).

${ }^{7}$ No contexto da retórica, a repetição pode aparecer em vários níveis da língua, sem que isso seja visto como vício ou excesso. Há razões diversas para a ocorrência, entre as quais a própria necessidade estrutural da língua. Os efeitos e a avaliação, em cada caso, dependem das relações interlocutivas nas várias esferas da vida social (cf. < http://www.radames.manosso.nom.br/retorica/repeticao.htm>).
} 
de "redundância" (tautologia, pleonasmo, sinonímia, paráfrase) e especificar suas semelhanças e discrepâncias em outro nível. Passemos, então, ao nível enunciativo e discursivo, considerando novamente que uma hiperlíngua, tal como perspectivada por Auroux, comporta uma língua empírica que só existe, espacial e temporalmente, através de sujeitos que convivem num mundo em que há artefatos técnicos tais como gramáticas e dicionários.

\section{Estudos EnUnCIATIVos E Discursivos}

No Dictionnaire d'Analyse du Discours (CHARAUDEAU; MAINGUENEAU, 2002) não se encontram os termos tautologia, pleonasmo, sinonímia (o primeiro, típico da lógica; os outros, encontráveis nas gramáticas) ${ }^{8}$. Encontra-se, no entanto, "paráfrase”, identificada como

[...] uma relação de equivalência entre dois enunciados, um podendo ser a reformulação ou não do outro. A equivalência se exprime em termos de correferência e mesmo de anáfora. Pode ser semântica e articular-se sobre a presença conjunta, nas duas expressões, de um núcleo semântico comum e de semantismos diferenciais ("o presidente da República"/"o chefe do Estado; "ele acreditou que"/"ele imaginou que"). Por essa razão, a paráfrase não poderia proceder da sinonímia, na medida em que ela solicita a deformabilidade do sentido em discurso [...]. A paráfrase pode igualmente apoiar-se sobre uma contiguidade formal entre os enunciados: relação entre ativa e passiva; estrutura elíptica vs desenvolvida; jogo sobre as modalizações ("é preciso que eu..."। "eu devo..."; "é interessante"|"não está mal”), etc. (Tradução minha).

Acentue-se aqui a observação de que paráfrase, supondo a "deformabilidade" do sentido no discurso, estaria distante da sinonímia, que surgiria de movimento contrário: busca-se a aproximação de sentido.

Fuchs (1994) não aceita que haja equivalência semântica fechada: trata-se, para ela, de "parentesco semântico", comparável à ideia de "ar de família" (Wittgenstein), que resulta de trabalho dinâmico sobre as significações (FUCHS, 1994, p. 129). Assim, ela explica que não se trata de dizer se dois enunciados são ou não paráfrases um do outro, mas "em que condições interpretativas eles poderiam ser tratados como tais." (FUCHS, 1994, p. 130, grifo da autora).

\footnotetext{
${ }^{8}$ Em síntese, tautologia aparece assim definida no The Cambridge Dictionnary of Philosophy (1999, p. 902-903): "uma proposição cuja negação é inconsistente, ou (auto)-contraditória, por exemplo, 'Sócrates é Sócrates', 'Todo humano é macho ou não-macho'. [...] Tautologias são logicamente necessárias e contradições são logicamente impossíveis." Do ponto de vista gramatical, a tautologia é encarada como vício.
} 
Maingueneau (1991) enquadra a parafrasagem como uma operação metadiscursiva - um jogo no interior do próprio discurso ${ }^{9}$. Em qualquer espaço discursivo o sentido é apreendido no deslizamento de uma expressão a outra no interior do que seriam classes de equivalência. Um enunciador pode realizar "metapredicações" a exemplo de: isto quer dizer, em outras palavras, ou melhor..., propondo com isso uma operação discursiva para identificar expressões postas lado a lado. Essa operação implica o distanciamento do enunciador relativamente a seu próprio discurso. A reformulação parafrástica aparece como uma tentativa de transpor obstáculos de caráter interacional, mais especificamente de compreensão do discurso por parte do outro. Para a Análise de Discurso, trata-se de associar as possibilidades de parafrasagem às possibilidades do arquivo correspondente ${ }^{10}$. Em suma: parafrasear representa uma tentativa de controle da polissemia permitida pela língua e pelo interdiscurso. Busca-se, com a reformulação, bloquear a proliferação de sentidos que uma expressão pode evocar (ou provocar). Nesse sentido, e como operação discursiva que é, a parafrasagem, diz Maingueneau, não é discursivamente neutra. Acrescento aqui que o processo, em certo grau, está vinculado à construção de autoria na formulação discursiva.

Fuchs (1982, p. 29-30) afirma:

[...] o que poderia passar, do ponto de vista do estrito "sentido linguístico", por uma identidade de sentido funciona sempre, na prática discursiva concreta, como um adiantamento, como um deslocamento de sentido. Há sempre progressão discursiva, argumentativa, jamais real repetição ou tautologia, ou simples decalque do sentido: o sentido do texto-fonte decodificado, reconstruído pelo sujeito não é jamais reproduzido idêntico, mas sempre re-re-construído (Tradução minha, grifos meus).

Retornar ao já dito na formulação de um discurso possibilita, por um lado, a manutenção, no enunciado, de algo que é fonte, espaço de memória (previsibilidade); por outro lado, ao se enunciar o sujeito procede a uma reformulação, abrindo espaço para o novo. O processo estabelece uma constante tensão entre retomada e diferenciação.

Daí chego a três pontos que merecem discussão:

\footnotetext{
“[...] num enunciado nem tudo é produzido no mesmo comprimento de onda: o dito pode ser constantemente atravessado por um metadiscurso mais ou menos visível que manifesta um trabalho de ajuste dos termos a um código de referência" (MAINGUENEAU, 1991, p. 145).

10 O objeto da $\mathrm{AD}$, conforme Maingueneau (1991), é o arquivo, que agrupa um conjunto de inscrições relativas a um mesmo posicionamento subjetivo. A análise de arquivo deve mostrar certa organização do universo de uma coletividade, implicada em seus textos, que mostram um modo específico de existência para um conjunto de enunciados (que podem ser re-ditos).
} 
a redundância de expressões que examino seria então o limite superior (o exagero) da paráfrase?

b) Fuchs (1982, p. 29) diz que a reformulação pode percorrer todo o campo semântico, desde a repetição literal ao completamente Outro (contradição frontal), passando por vários graus de semelhante/não semelhante. "Tudo (mas não qualquer coisa!) pode reformular um discurso-fonte, por um sujeito, numa situação dada."

c) se todo deslocamento puder ser chamado por extensão "metáfora", eis aí mais um caso de metáfora.

Há outro aspecto interessante no posicionamento de Fuchs (1982, p. 30): ela diz que Culioli fala da tradução como caso-limite da parafrasagem, e observa que no discurso de vulgarização científica há uma atividade aparentada à tradução (uma tradução em linguagem cotidiana). Assim, paráfrase, tradução, reformulação, redundância se aproximam semanticamente nesse contexto - tudo isso funcionando como metadiscurso (seu hiperônimo).

Esclareço que Fuchs trata a paráfrase na perspectiva de uma linguística enunciativa, entendendo o enunciado como unidade elementar da discursivização, o qual pode ser descrito a partir de certo número de “categorias de língua”. Por enunciação (em sentido estrito) ela entende

[...] o conjunto das operações regulares de constituiçãointerpretação dos enunciados apreensíveis por referência aos parâmetros lingüísticos - ou seja, necessariamente idealizados constitutivos da situação de enunciação (enunciador, coenunciador, momento da enunciação [...] (FUCHS, 1994, p. 84).

Ela considera que a plurivocidade está inscrita no centro da problemática da interpretação dos enunciados. Um termo-chave no tratamento da paráfrase, para ela, é deformabilidade, ou seja, o que se consideraria uma deformação semântica do ponto de partida, por interpretação (e nesse caso se pensaria no ideal de univocidade). É comum que se diga que certas interpretações "distorceram" um texto. Assim, uma operação discursiva pode ser a prevenção do enunciador quanto à possibilidade de deformação. Daí as "pistas interpretativas”, que se supõe, podem retificar certa direção de interpretação e também bloquear certas extensões semânticas de um termo polissêmico (cf. FUCHS, 1994, p. 109). Afinal, a interpretação sempre implica uma margem de jogo.

Visto que a noção de paráfrase direciona para aquela de reformulação, retomo alguns elementos dos estudos discursivos.

A reformulação aparece como uma relação de paráfrase. Ao retomar um dado, o locutor utiliza-se de uma expressão diferente daquela usada para uma referenciação anterior (note-se agora a ocorrência de referenciação, que deverá ser contrastada com referência) (v. CHARAUDEAU; 
MAINGUENEAU, 2002, p. 490). Eis algumas funções da reformulação:

a) criar tópicos discursivos isotópicos por meio de deslocamentos semânticos: Teu gato... O bichinho... Esta fera... ${ }^{11}$;

b) enunciativamente, retomar, reformulando, o discurso de outrem ou o seu mesmo, através do discurso relatado fenômeno dialógico, no sentido de Bakhtin, o que envolve a heterogeneidade do discurso;

c) imitar ou explicar; na imitação, a reformulação se prende ao significante (a paródia, por exemplo); na explicação, o texto-fonte é reformulado em seu sentido para a produção de um texto-alvo, refletindo de alguma forma o sentido do primeiro (definições explicitadas, resumos, sínteses).

$\mathrm{Na}$ análise do discurso, o processo de reformulação remete à ordenação de tópicos intradiscursivos através da anáfora e da catáfora (em suas várias modalidades: pronominal, lexical - de que não vou me ocupar aqui).

No campo enunciativo, a referência (tendo como contraparte o referente) $)^{12}$ é posta em contraste com referenciação, dada como uma atividade cognitiva e discursiva, numa visão não referencial da língua - o que significa que se concebe a realidade como algo construído, mantido ou alterado a partir de como o mundo é nomeado numa cultura e como as pessoas interagem com ele (não se deve inferir daqui que se nega a existência da realidade):

A referência passa a ser considerada como o resultado da operação que realizamos quando, para designar, representar ou sugerir algo, usamos um termo ou criamos uma situação discursiva referencial com essa finalidade: as entidades designadas são vistas como objetos-de-discurso e não como objetos-do-mundo (KOCH, 2002, p. 79).

Esta citação remete, no contexto de minha reflexão, à possibilidade de que os "objetos de discurso" são pensados e formulados com algum grau de imprecisão relativamente ao que seriam os "objetos de mundo" referidos, o que, dada a relação interlocutiva, acaba levando a rearranjos de formulação - rearranjos que podem, nos vários campos, sofrer estabilização.

\footnotetext{
${ }^{11}$ A isotopia (conceito criado por Greimas em 1966 em sua semântica estrutural) diz respeito aos procedimentos que conduzem à coerência de uma sequência discursiva ou mensagem. Ela está centrada sobre a redundância de traços no desdobramento dos enunciados, favorecendo a legibilidade dos textos (cf. CHARAUDEAU, MAINGUENEAU, 2002, p. 332).

${ }^{12}$ A referencia seria a propriedade do signo linguístico de remeter a uma realidade, e referente à realidade apontada pela referência (ou fabricada pela prática social?).
} 
No caso dos dados que compõem o corpus em estudo, não parece tratar-se meramente de "discurso-fonte retomado". Mesmo na linguagem escrita esse tipo de iteração é comum, e considero esse fenômeno associado àquele de uma forma do metadiscurso - como já observado - ocorrente com as expressões: isto é, ou melhor, em outras palavras e similares, que não reúnem palavras sinônimas (às vezes são uma tradução), mas constituem um processo explicativo que tem a ver, certamente, com controle da expressão - controle da linguagem associando eu e tu, indo em direção ao destinatário; controle das possibilidades de equívoco; controle de comunicação por estratégias discursivas, tendo em vista o conhecimento que se tem das possibilidades de interpretação - o que também é possível relatar a uma estratégia de autodefesa, sobretudo em casos de audiência pouco conhecida ou não conhecida. Aqui, contudo, a característica é a ausência dos metapredicados (elementos de controle). Combina-se, assim, redundância e abreviação, de modo que o efeito mais evidente é o de que se repete viciosamente, como se verá nos dados.

Seria possível ainda, no campo da redundância, fazer analogia com a construção do tipo "O estabelecimento/implementação deste novo projeto...", bastante comum na escrita formal em trabalhos especializados. Exemplos de uso real:

- "O trabalho de construção/produção indicado nos fragmentos citados encontra-se diretamente ligado à historicidade dos sentidos..." (trabalho acadêmico)

o "[...] o debate acerca das falácias de toda e qualquer idéia de ordenação/hierarquização entre um significado fixo ao qual viria se acrescentar um sentido (acessório) mutante [...]" (trabalho acadêmico)

Outra possibilidade na mesma linha é o encadeamento da formulação parafrástica com ou, bem como por justaposição:

o " [...] se dizemos que os sentidos circulam, é porque queremos rejeitar um entendimento segundo o qual se diria que os sentidos são fixos, imutáveis, ou que são passíveis de serem localizados em algum ponto preciso do fio do discurso." (Trabalho acadêmico)

- "[...] se digo que o enfoque da Análise de Conteúdo privilegia uma versão do sentido como algo de mais estável, de menos movente, é porque [...]". (Trabalho acadêmico)

Em todos esses casos observa-se um processo de antecipação que está vinculado às imagens feitas de outrem pelo produtor, que responde a eventuais dúvidas do interlocutor antes que ele (eventualmente) se manifeste, quem sabe poupando-o de uma busca no dicionário, por exemplo.

Fuchs (1994) afirma que não se pode falar em equivalência semântica a não ser no quadro de uma semântica vericondicional, que opera sobre esquemas de frases supostamente unívocas. Ora, não é isso que 
acontece nas práticas discursivas, em que se trata de relação entre enunciados, e não frases (sentido gramatical).

Nesse sentido, vou examinar a concepção de enunciado que aparece no contexto do sociointeracionismo do Círculo de Bakhtin. La structure de l'énoncé é o segundo texto previsto para uma obra sobre a estilística do discurso artístico - que não teve a publicação concluída. Ele é assinado por Voloshinov e apareceu na Rússia em 1930. Utilizo-me dele para explorar a compreensão da estrutura do enunciado pelo Círculo.

Toda expressão linguística se caracteriza por sua "orientação para o outro" - quer dizer, ela é o resultado de um fenômeno com dupla face: de um lado, o locutor; de outro, o ouvinte/leitor, fisicamente presente ou não. A unidade concreta de que se trata aqui é o enunciado, que surge enquadrado na vida social em amplos círculos, do mais abrangente ao mais restrito, que podem ser resumidos num esquema assim apresentado por Voloshinov: 1) Organização econômica da sociedade; 2) Relação de comunicação social; 3) Interação verbal; 4) Enunciados; 5) Formas gramaticais da linguagem.

O enunciado comporta, necessariamente, além da parte verbal expressa, também uma parte extraverbal, que é formada pelo auditório e pela situação social em questão. Ele é uma unidade de comunicação e uma totalidade semântica; apresenta-se na forma de um gênero. Na situação concreta, a expressão que compõe enunciado é completada pelo gesto, por uma ação, por uma resposta. Além de haver esse complemento situacional, Voloshinov enfatiza que também há um começo de natureza extraverbal: 0 enunciado supõe o contato com o meio extraverbal, e mais: o discurso de outrem. Os gêneros existentes não estão acabados, mas se é possível falar deles é que formas mais ou menos estáveis podem ser reconhecidas, dado o modo de vida das comunidades e as circunstâncias de uso.

A orientação social é precisamente uma dessas forças vivas e constitutivas que, ao mesmo tempo que organizam o contexto do enunciado - a situação -, determinam também sua forma estilística e sua estrutura estritamente gramatical (VOLOSHINOV, [1930] 1981, p. 299, tradução minha).

Os modos de ser, as atitudes das pessoas em sociedade são, para Voloshinov, "a expressão gestual da orientação social do enunciado." ( $\mathrm{p}$. 299, grifos do autor). Também aí entra o tom/entonação, o ritmo da elocução, marcas destacadas especialmente na enunciação oral.

Dando mais um passo, o autor acrescenta ao enunciado o seu conteúdo, que vai além da mera sonoridade, que pode estar distanciada do caráter estrito de linguagem. Enunciados reais têm sentido (que também é chamado tema). Assim, expressões curtas que poderiam ser proferidas em situações até mesmo divergentes podem ser constituintes de enunciados distintos - de eventos distintos - com material linguístico idêntico; digamos "Que coisa!" Acontece isso nas expressões ditas "redundantes"?

Em resumo, três aspectos subentendidos formam a parte 
extraverbal do enunciado (a situação): espaço e tempo do evento, tema do enunciado e a posição dos interlocutores em relação ao evento enunciativo (a avaliação que dele fazem). Essas são as condições de produção dos enunciados. No caso da produção ou incorporação de redundâncias devemos admitir que parte do processo é subsumido pelos gestos de orientação social do enunciado, estando a discursividade moldada, pelo menos parcialmente, pela formulação estabilizada na memória discursiva.

\section{Análise, Discussão e Proposta de Compreensão da "REDUNDÂNCIA"}

É considerando as condições de produção que seria possível, num primeiro momento, justificar de modo genérico as recorrências manifestadas no discurso. Entretanto, há recorrências sutis, como as estruturais, que ninguém consideraria errôneas por serem constitutivas da língua (cf. a duplicação de pessoa em nós chegamos; de gênero em a garota), e, indo em direção ao outro polo, aquelas que têm um efeito negativo na percepção dos sujeitos. Como observa Manosso [s.d.], a repetição "de palavras de largo uso como a das classes gramaticais fechadas (artigos, preposições, pronomes) só é percebida se houver outro fator favorável como proximidade ou frequência alta." É o que tenho observado, aliás, com relação ao indefinido um(a), como se constata no exemplo:

o $\quad$ “...o texto que a professora [...] escolhera para leitura com seus alunos era uma notícia no jornal que relatava uma condenação de uma diretora de escola local por crime de segregação racial." (Trabalho acadêmico, 1993).

Em última análise, quem poderia afirmar a existência de regras infalíveis para separar, na repetição, o espectro positivo daquele do vício? Entretanto, se a avaliação é subjetiva, a circulação de material dito 'redundante' com crítica apensa (e comentários irônicos) tende a provocar em leitores menos avisados uma atitude também de crítica, passando ao largo a tentativa de explicar ou entender por que há tantas ocorrências. E assim como aparecem as críticas, há as réplicas, através das quais se rebate a aparente certeza de que no uso o sentido é tão óbvio que nada justifica a repetição.

Listas como a que segue são comuns (trago apenas uma amostra):

o Habitat natural. (Todo habitat é natural; consulte um dicionário.) ${ }^{13}$

o $\quad$ Conviver junto. (É possível conviver separadamente?)

\footnotetext{
${ }^{13}$ Note-se: Derivação: por extensão de sentido. Local onde algo é ger. encontrado ou onde alguém se sente em seu ambiente ideal. Ex.: ao ser admitida na biblioteca, ela encontrou o seu h (HOUAISS, 2001).
} 


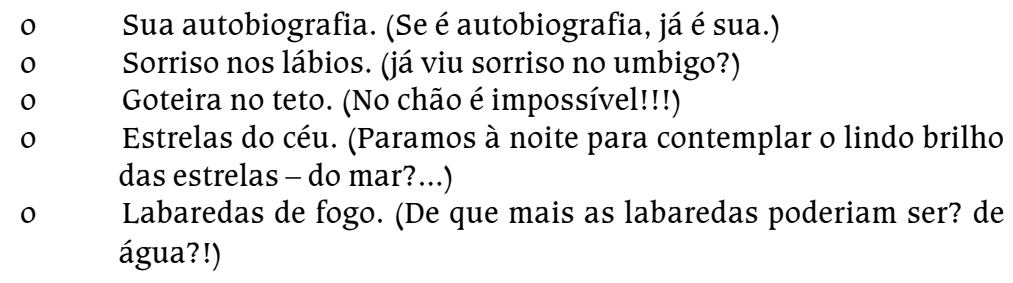

Indo um pouco além das tentativas de mostrar por que não há necessariamente repetição viciosa nessas expressões, observo que a crítica é comumente superficial e se limita a construções simples, aparentemente desconsiderando o contexto e, o que é mais importante, implicitando a crença a-histórica de que a linguagem é transparente, com sentido unívoco - ou, no máximo, valeria apenas o sentido que o usuário crítico lhe atribui naquele momento. E a esse comentário agrego o de um membro da Comunidade Virtual de Linguagem (CVL - Yahoo), Carlos Eduardo Castanheira, em email enviado em 16/02/2002, quando o tema era discutido na comunidade: "a linguagem escapa graciosamente pelos fios da rede dos tiranos." o próprio dicionário como instrumento linguístico pode desdizer a pretensa uniformidade semântica. Retiro do Houaiss (2001) só um exemplo (goteira), com apenas duas das onze acepções:

1 nos beirais, cada uma das bicas pelas quais goteja ou se concentra a água dos telhados, quando chove

2 cano destinado a captar essas águas pluviais; calha

Minha proposta não recusa terminantemente que não haja uso vicioso, mas isso se daria numa escala fluida, que leva em conta a recepção subjetiva (do imperceptível - normal, não normativo - até o inaceitável, pelo uso com certo exagero no nível formal da escrita). Considere-se ainda que o acontecimento discursivo corresponde à formulação de um enunciado em contexto único. Nesse sentido, o próprio dicionário pode ser concebido como o típico instrumento da redundância...

Segue uma lista (recorte do corpus) de expressões e recortes discursivos em que o processo de repetição se evidencia. Tento mostrar, ainda, com um pequeno conjunto de dados, um traço que me chamou a atenção na repetição encontrada em grande número de expressões utilizadas na escrita formal (que não é homogênea), muitas delas de trabalhos acadêmicos (TA), coletadas de 1990 até hoje: repete-se o que fica implícito quer dizer, explicita-se:

(1) identificação da localização (do problema)

(2) levantamento prévio anterior (a respeito dos jornais...)

(3) acentuar com ênfase / salientar sobremaneira

(4) justificar o porquê

(5) propriedades intrínsecas fundamentais 
(6) importado do exterior

(7) despencar despenhadeiro abaixo (escrito popularizado)

(8) frases que ilustram alguns exemplos de problemas

(9) resumir de maneira curta $^{14} /$ resumir de forma sucinta

(10) tirar proveitos bastante positivos

(11) mesa abundantemente farta

(12) pré-requisitos básicos

(13) centrar foco quase exclusivo

(14) marco de referência

(15) alicerce fundamental

(16) necessidade essencial

(17) ser perfeitamente exata

(18) identificação clara

(19) atentar mais de perto

(20) novas novidades / novos custos adicionais

(21) ensaiar uma tentativa

(22) jornada de seis horas diárias ${ }^{15}$

(23) "As referências concretas para essa convertibilidade possível das mercadorias trocadas mundialmente deixam de ser necessariamente o Estado-Nação." (Trabalho acadêmico $\left.{ }^{16}, 1998\right)$

(24) "Relações estas que [...] indicam a presença de uma formação ideológica de subordinação conformada com o já instituído." (TA, 1999)

(25) "Não se trata, adianto de antemão, de alimentar a velha polêmica, porém muito mais propriamente, de nos alimentarmos dela." (TA, 1998)

(26) “...esse fenômeno chega a atingir, aproximadamente, uma média de 63\%." (TA, 2001)

(27) "...escrevo para informar que há cerca de mais ou menos um mês, deixei de receber os e-mails da comunidade virtual de linguagem." (Membro de comunidade virtual, 2002)

(28) “... demonstra que a posição de determinado evento linguístico não precisa obrigatoriamente ser idêntica nos três continua, isto é, um evento pode ser ao mesmo tempo,..." (TA, 2000)

(29) "Não é óbvio e evidente?" (TA, 2000)

(30) “... apresentando flashbacks de sua vida anterior... (TA traduzido, 2001)

(31) "Um paralelo comparativo entre inteligência e criatividade" (TA, 2001)

(32) "As generalizações precedentes, por mais úteis que sejam para

${ }^{14}$ Um contexto possível: implicita-se que um pretenso resumo tenha ficado longo, e reforçase que se trata de algo realmente curto.

15 Este caso, mais sutil, mostra como o ajuste semântico pode acabar neutralizando a redundância: uma jornada não implica mais a referência a um único dia: pode ser mensal, anual... pode tratar-se de caminhada, uma viagem (especialmente por terra). Nesse caso, contudo, a referência a 'dia' é explicitada.

${ }^{16}$ Doravante TA. 
revelar um panorama de conjunto, nem por isso são plenamente satisfatórias." (TA traduzido, 2001)

“... as formas em -mente apresentam características peculiares em confronto com as demais formações sufixais em português." (TA, 1998)

“... para não incorrer no mesmo equívoco que se condena, no decorrer de todo o livro frisa-se de modo enfático que os textos orais estão em ordem, não são caóticos..." (TA, 2001)

"...Orlandi afirma que em seu trabalho eles têm uma especificidade própria." (TA, 1996 em diante; referência aos conceitos de Real, Simbólico, Imaginário da teoria de Lacan)

"Agora, sentimos a necessidade de precisar melhor essa nossa afirmação." (TA, 1998)

"A AD vai trabalhar com a contradição entre estas duas forças: a vontade de hipertrofia e a submissão ao assujeitamento."

"Na intenção de resumir, de forma sucinta, como se forma uma criação analógica, ..." (TA, 1997)

No Quadro 1, um teste preliminar mostra, pela parafrasagem, a regularidade na formulação de um número significativo de construções "redundantes". Esta é apenas uma face do fenômeno em estudo, que apresento aqui como estágio inicial da exploração feita. Acaba-se, paradoxalmente, podendo especificar a redundância pelo seu oposto: uma paráfrase abreviada, que indica a aparente necessidade de buscar traços isotópicos.

\section{QUADRO 1 - A REDUNDÂNCIA COMO FORMA PARAFRÁSTICA ABREVIADA}

\begin{tabular}{|c|c|c|}
\hline 1. Expressão & 2. Especificação semântica & 3. Forma parafrástica \\
\hline Pré-requisitos (1) básicos (2) & $\begin{array}{l}\text { (1) requisito essencial } \\
\text { (2) fundamental, essencial }\end{array}$ & $\begin{array}{l}\text { Pré-requisito, ou seja, elemento } \\
\text { básico }\end{array}$ \\
\hline Centrar (1) foco (2) quase exclusivo & $\begin{array}{l}\text { (1) ajustar o foco/focalizar } \\
\text { (2) ponto central de onde provém } \\
\text { algo }\end{array}$ & $\begin{array}{l}\text { Centrar, quer dizer, pôr o foco } \\
\text { em algo }\end{array}$ \\
\hline Marco (1) de referência (2) & $\begin{array}{l}\text { (1) sinal de demarcação, ponto de } \\
\text { referência } \\
\text { (2) indicação, marca }\end{array}$ & $\begin{array}{l}\text { Um marco, ou seja, uma } \\
\text { referência. }\end{array}$ \\
\hline alicerce (1) fundamental (2) & $\begin{array}{l}\text { (1) base, fundação, fundamento } \\
\text { (2) que serve de alicerce, básico, } \\
\text { essencial }\end{array}$ & $\begin{array}{l}\text { Um alicerce, isto é, uma peça } \\
\text { fundamental }\end{array}$ \\
\hline Panorama (1) de conjunto (2) & $\begin{array}{l}\text { (1) visão ampla, em todas as } \\
\text { direções, de uma área extensa } \\
\text { (2) certa quantidade de elementos } \\
\text { vistos como um todo }\end{array}$ & $\begin{array}{l}\text { Um panorama, isto é, uma visão } \\
\text { de elementos como um todo. }\end{array}$ \\
\hline $\begin{array}{l}\text { Levantamento prévio (1) anterior } \\
\text { (2) }\end{array}$ & $\begin{array}{l}\text { (1) anterior, antecipado, preliminar } \\
\text { (2) que aconteceu ou foi feito } \\
\text { antes/previamente }\end{array}$ & $\begin{array}{l}\text { Um levantamento prévio, ou } \\
\text { seja, feito anteriormente. }\end{array}$ \\
\hline
\end{tabular}


Esse processo, ainda que possa não guardar uniformidade para o material coletado (nem é o que se espera), tem uma curiosa relevância, quando se considera a memória discursiva dos acontecimentos - que não se inscrevem no vazio da história, mas num mundo povoado de todo tipo de referências: sociais, míticas, históricas, simbólicas, enfim. Pêcheux (1999) referencia a memória como estruturação da materialidade discursiva, posta aqui numa dialética da repetição e da regularização:

[...] a memória discursiva seria aquilo que, face a um texto que surge como acontecimento a ler, vem restabelecer os "implícitos" (quer dizer, mais tecnicamente, os pré-construídos, elementos citados e relatados, discursos-transversos, etc.) de que sua leitura necessita: a condição do legível em relação ao próprio legível (PÊCHEUX, 1999, p. 52).

Como interpretar essa referência? Entendo que os implícitos, estando na memória, permitem que não se diga tudo - o que é impossível -, mas a leitura dos textos é possibilitada pela memória. Não se tratando, porém, de uma memória individual, sempre haverá lacunas do ponto de vista subjetivo, ou melhor, a leitura depende substancialmente de quem interpreta, daí que, na posição-leitor, o sujeito apresenta graus de leitura (da mesma forma que, na função-autor, há graus de autoria). Na perspectiva assumida por Pierre Achard, retomado por Pêcheux nesse mesmo texto, os implícitos tomariam a forma de remissões, de retomadas, de efeitos de paráfrase (tal como temos aqui, com as redundâncias, de um modo particular), mas sem haver nada estabilizado, visto que o encontro dos elementos de memória com o acontecimento atual tende a provocar conflito, a perturbar a memória. Pêcheux (1999, p. 52) explica isso com estas palavras: "o acontecimento, no caso, desloca e desregula os implícitos associados ao sistema de regularização anterior".

No caso em pauta, exemplificado pela regularidade do processo apresentada no Quadro 1, tem-se um jogo de implícitos particular: uma forma parafrástica abreviada tal como atualizada na primeira coluna, que por sua vez, na forma de redundância comumente avaliada de modo negativo, produz uma estrutura com implícitos e tende a tornar-se regular (constatase isso pela recorrência no uso).

\section{CONSIDERAÇÕES}

Após essa tentativa de compreensão dos eventos de redundância, examinando-se as questões levantadas no início e durante o percurso, percebese, em primeira instância, que não se trata meramente de "esvaziamento" semântico a justificar a repetição. Ora, a língua de que se trata aqui tem um funcionamento discursivo, ela só existe através de sujeitos: é uma 
hiperlíngua (em nosso caso, o brasileiro), e como tal há um dinamismo irrefreável nela. Como para outros "vícios" encontrados nela, a repetição tem um lado solenemente gramatical: a concordância. E, como ficou perceptível, a parafrasagem, como fenômeno metadiscursivo "normal", tem na redundância fenômeno análogo; a parafrasagem aparece como uma das faces da redundância.

Inconscientemente ou não na construção subjetiva, a redundância oferece uma garantia de legibilidade, e representa uma tática de endereçamento bem-sucedido para o destinatário, ainda que este opte por um julgamento de valor negativo na negociação dos sentidos. Os modos de ser - por estar o sujeito imerso na sociedade - são, como expressou Voloshinov, a expressão gestual da orientação social do enunciado. E a interpretação (de quem produz, de quem recebe) também é um gesto. Nesse jogo, importa mais a tensão entre identidade e alteridade, e menos a concepção atada a uma pretensa autonomia da língua, que a olha como uma dama aviltada, e que fica profundamente agradecida por não a deturparem ("A língua portuguesa agradece..."). Quanto ao que se consideraria excesso (ou vício), numa hiperlíngua, disse-o Auroux, os sujeitos podem ser desde muito conservadores até muito liberais em seus julgamentos.

\title{
RESUMO
}

Este trabalho é parte de uma pesquisa sobre as tendências à deriva na escrita formal do português brasileiro, buscando estudar as implicações normativas e consequências para a pedagogia da língua. Está centrado no estudo das chamadas "redundâncias". Discuto algumas hipóteses a respeito do funcionamento discursivo das redundâncias: 1. ocorre esvaziamento semântico de palavras, o que justifica a "repetição"; 2. a parafrasagem na formulação discursiva é uma das faces da redundância; 3 . as redundâncias previnem a possibilidade de deformação ao ser feita a interpretação. Investigo, assim, a plurivocidade inscrita nos enunciados e o jogo entre identidade e alteridade que aí se observa.

Palavras-chave: escrita formal; redundância; efeitos semânticos.

\begin{abstract}
The present work is part in a research on the trends adrift in Brazilian Portuguese formal writing, in order to investigate the normative implications and consequences for the pedagogy of that language. It is focused on the so called "redundancies". I discuss some of the hypotheses about the discursive working
\end{abstract}


of the redundancies: 1 . a semantic emptying out of the words occur, thus justifying "repetition"; 2 . to paraphrase in a discursive formulation is one of the sides of redundancy; 3 . redundancies prevent the possibility of deformation at the moment of interpretation. Thus, I investigate the plurivoicing in the enunciations and the play between identity and alterity there observed.

Keywords: formal writing; redundancy; semantic effects.

\section{REFERÊNCIAS}

AUDI, R. (Ed.). The Cambridge dictionary of philosophy. 2. ed. Cambridge: Cambridge University Press, 1999.

AURouX, S. A "hiperlíngua" e a externalidade da referência. In: ORLANDI, Eni (Org.). Gestos de leitura: da história no discurso. Campinas: Ed. da UNICAMP, 1994. p. 241-251.

30, jan.-jun. 1998.

. Língua e hiperlíngua. Línguas e Instrumentos Lingüísticos, Campinas, n. 1, p. 17. A revolução tecnológica da gramatização. Tradução de: Eni P. Orlandi. Campinas:

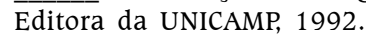

AUTHIER, J. Ces mots qui ne vont pas de soi: boucles réflexives et non-coïncidences du dire. 2 tomes. Paris: Larousse, 1995.

Charaudeau, P.; Maingueneau, D. Dictionnaire d' analyse du discours. Paris: Seuil, 2002.

CUNHA, C.; CINTRA, L. L. Nova gramática do português contemporâneo. 2. ed. 35. impr. Rio de Janeiro: Nova Fronteira, 1997.

FRANCHI, C. Criatividade e gramática. In: POSSENTI, S. (Org.). Mas o que é mesmo "gramática"? São Paulo: Parábola, 2006. p. 34-101.

FUCHS, C. La paraphrase entre la langue et le discours. Langue Française, Paris, n. 53, p. 22-33, fév. 1982.

. Paraphrase et énonciation. Paris: Ophrys, 1994.

GADET, F. Tricher la langue. In: CONEIN, B. et al. Matérialités discursives - Colloque des 24, 25, 26 avril 1980. Lille: Presses Universitaires de Lille, 1981. p. 117-126.

HOUAISS, A. Dicionário eletrônico Houaiss da língua portuguesa. Versão 1.0. Rio de Janeiro: Ed. Objetiva, 2001.

KOCH, I. V. Desvendando os segredos do texto. São Paulo: Contexto, 2002.

MAINGUENEAU, D. L' analyse du discours. Paris: Hachette, 1991.

MARCONDES FILHO, C. O espelho e a máscara: o enigma da comunicação no caminho do meio. São Paulo: Discurso Editorial; Ijuí: Editora Unijuí, 2002.

ORLANDI, E. P. Análise de discurso: princípios e procedimentos. Campinas: Pontes, 1999. . (Org.). História das idéias lingüísticas: construção do saber metalingüístico e constituição da língua nacional. Campinas: Pontes; Cáceres: UNEMAT Editora, 2001. 


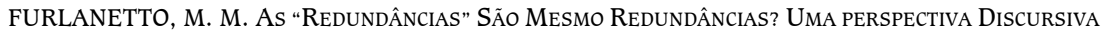

PÊCHEUX, M. Papel da memória. In: ACHARD, P. et al. Papel da memória. Campinas: Pontes, 1999. p. 49-57.

PINHEIRO, J. M. S. Conceitos de redundância e contingência. 2004. Disponível em: < http:/ /www.projetoderedes.com.br/artigos/artigo_conceitos_de_redundancia.php $>$. Acesso em: $6 / 06 / 2007$.

POSSENTI, S. A cor da língua e outras croniquinhas de linguística. Campinas: Mercado de Letras/ALB, 2001.

VOLOSHINOV, V. N. La structure de l'énoncé. In: TODOROV, T. Mikhail Bakhtine - le principe dialogique. Suivi de Écrits du Cercle de Bakhtine. Paris: Editions du Seuil, [1930] 1981. p. 287-316.

Submetido em: 17/11/2008.

Aceito em: 05/10/2009. 